\title{
Total Synthesis of a Docosahexaenoic Acid Prostanoid Using an Intramolecular Organocatalytic Michael Reaction of a Formyl-Enal Derivative
}

\author{
Johanna Revol-Cavalier, Valérie Bultel-Poncé, Alexandre Guy, Thierry Durand, Camille Oger,* \\ and Jean-Marie Galano*
}
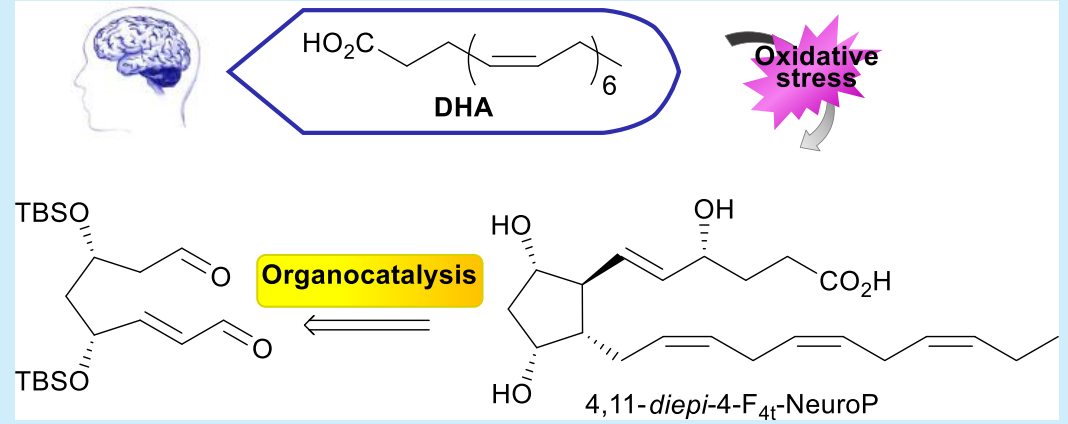

ABSTRACT: The total synthesis of a docosahexaenoic-acid-derived prostaglandin, 4,11-diepi-4- $\mathrm{F}_{4 \mathrm{t}}$-neuroprostane, featuring a complex lateral chain was achieved for the first time. A novel prostaglandin cyclopentane skeleton obtained via an intramolecular highly selective organocatalytic Michael sequence of a formyl-enal derivative allowed the desired and exclusive thermodynamic trans configuration of the lipidic lateral chains.

$\mathrm{P}$ rostaglandins (PGs) remain a souvenir of organic chemists, being forever embedded in the art of total synthesis thanks to the pioneering work of E. J. Corey ${ }^{1}$ and many other great chemists. ${ }^{2}$ For biochemists and biologists, the same holds true, as PGs remain the most studied oxygenated polyunsaturated fatty acid (PUFA) metabolites. ${ }^{3}$ The PGs fulfill a considerable number of research fields due to their original biosynthesis by cyclooxygenase enzymes (COXs), ${ }^{4}$ their biological actions as hormone-like compounds, ${ }^{5}$ their use as biomarkers of human diseases, and, finally, their therapeutic applications as drugs (synthetically modified or not) for human or animals.

In 1990 Morrow and coworkers discovered that autoxidation of phospholipidic arachidonic acid can also generate racemic $\mathrm{PGF}_{2 \alpha}$ together with its $\mathrm{C} 8$ isomer named $15-\mathrm{F}_{2 \mathrm{t}}$-isoprostane (Figure 1a). ${ }^{7,8}$ Docosahexaenoic acid (DHA) also autoxidizes into isoprostane structures (named neuroprostanes) and PGs, whereas interestingly, no known enzyme can produce PGs from DHA. ${ }^{9}$ Our group recently codiscovered the potent biological activity of $4-\mathrm{F}_{4 \mathrm{t}}$-neuroprostane $\left(4-\mathrm{F}_{4 \mathrm{t}}-\mathrm{NeuroP}\right)$, a DHA-derived isoprostane (Figure $1 \mathrm{~b}$ ) that protects the in vitro and in vivo post-translational modifications of the ryanodine receptor under oxidative conditions. ${ }^{10}$

This unprecedented biological activity for an organic compound makes it a formidable antiarrhythmic compound and a potential unique drug for ventilator-induced diaphragmatic dysfunction (VIDD). ${ }^{11}$ Thus because DHA PGs were never investigated nor synthesized in the past, this prompted us to synthesize one $4-\mathrm{F}_{4 \mathrm{t}}-\mathrm{NeuroP}$ counterparts, the 4,11-diepi4- $\mathrm{F}_{4 \mathrm{t}}$-neuroprostane 1 , to further evaluate the biological and analytical relevancies of unstudied PGs. Recent synthetic efforts in the synthesis of PG revealed the pertinent use of organocatalysis to construct advanced five-membered ring prostanoid skeleton intermediates. Aggarwal and coworkers developed a one-flask access to a key bicyclic enal intermediate ready for lateral chain introduction by the 1,4 addition of vinylcuprates or copper acetylide derivatives and Wittig reactions. ${ }^{12}$ Hayashi and coworkers also reported powerful organocatalytic cascade sequences for PG core skeletons, ${ }^{13}$ even to the point of establishing one side chain in the process. ${ }^{14}$ Novel synthetic methodologies were also applied for side-chain introduction, such as Baran decarboxylative alkenylation with an organozincderived olefin for both vinyl and allyl side chains in a recent 
a)<smiles>CCCCC[C@H](O)/C=C/C1[C@H](C/C=C/CCCC(=O)O)[C@@H](O)C[C@H]1O</smiles>

b)

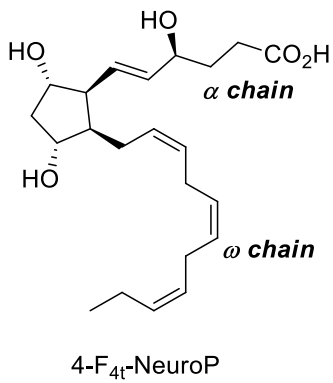

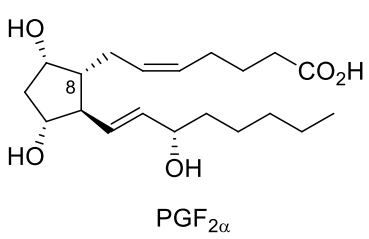

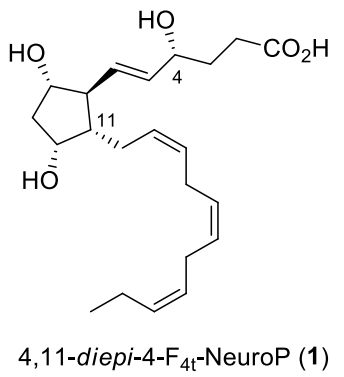

Figure 1. (a) $\mathrm{PGF}_{2 \alpha}$ and its $\mathrm{C} 8$ epimer (15- $\left.\mathrm{F}_{2 \mathrm{t}}-\mathrm{IsoP}\right)$. (b) Structures of 4- $\mathrm{F}_{4 \mathrm{t}}$-neuroprostane and 4,11-diepi-4- $\mathrm{F}_{4 \mathrm{t}}$-neuroprostane (1). By definition, the $\alpha$ chain in PGs has to be presented on top.

synthesis of $\mathrm{PGF}_{2 \alpha}{ }^{15}$ Stereoretentive cross-metathesis also proved successful for prostanoid synthesis to introduce Zalkene side chains with excellent geometric control. ${ }^{16}$

However, one particular feature of PGs derived from complex PUFAs (e.g., DHA) compared with the well-known $\mathrm{PGF}_{2 \alpha}$ is the inherent sensitivity of skipped diene units $(\omega$ chain in 1) (Scheme 1). Precursors of such side chains cannot

Scheme 1. Retrosynthesis of 4,11-diepi-4-F $\mathrm{F}_{4 \mathrm{t}}-\mathrm{NeuroP} 1$

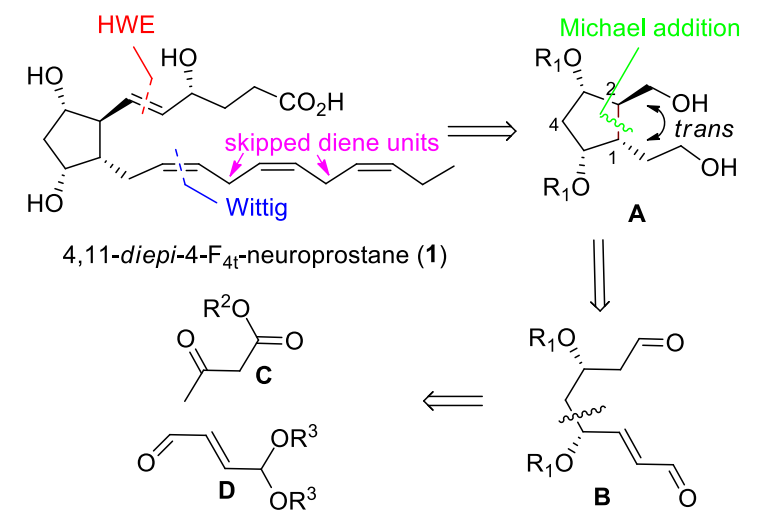

accommodate cuprate or organozinc preparation, and crossmetathesis with an advanced acyclic 1,4-diene precursor cannot be accomplished without the formation of the favored 1,4-cyclohexadiene product. The Corey lactone, famously known for PG synthesis, could seem ideally suited for 1; however, its lactone functionality may temper this idea. Indeed, the Wittig reaction conditions for the skipped diene unit of 1 are not compatible with such a lactol unit (lactol-aldehyde equilibrium not favored) because of the very low temperature required for this sensitive phosphonium-ylide reagent. The alternative would be a four-step sequence to convert the protected lactol and release the aldehyde functionality. This conundrum was observed and solved during our effort in the synthesis of $4-\mathrm{F}_{4 \mathrm{t}}-\mathrm{NeuroP}$ (epimer of $\mathbf{1}$ ) ${ }^{17 \mathrm{a}}$ with the help of a 1,5-pentadiol unit such as $\mathbf{A}$ (albeit with a 1,2-cis configuration) together with a novel regioselective enzymatic monoprotection. ${ }^{19 \mathrm{~b}}$ Structure $\mathrm{A}$ can thus be the perfect

intermediate for our synthesis. This useful intermediate would arise from the formyl enal system $\mathbf{B}$ following a rare organocatalytic intramolecular Michael addition. ${ }^{18-20}$ An asymmetric aldol reaction between synthons $\mathbf{C}$ and $\mathbf{D}$ should provide the requisite 1,3 -hydroxy unit. $^{21}$

Our endeavor started with the synthesis of the dimethylacetal of fumaraldehyde $2,{ }^{22}$ following an inexpensive slightly modified protocol, from dimethoxyfuran in two steps on a large scale ( $51 \%$ yield) (Scheme 2$).{ }^{23}$ Implementation of the

Scheme 2. Asymmetric Synthesis of Formyl-Enal Derivative 6

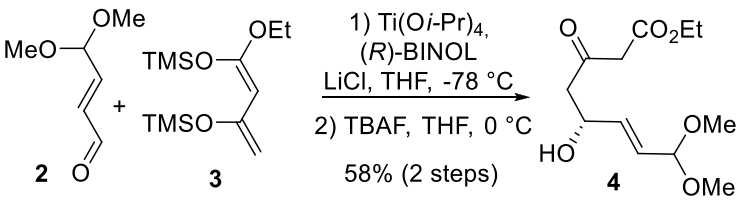

$$
\begin{aligned}
& \mathrm{BEt}_{2}(\mathrm{OMe}), \mathrm{NaBH}_{4} \\
& \mathrm{MeOH} / \mathrm{THF},-78^{\circ} \mathrm{C} \\
& \text { then } \mathrm{H}_{2} \mathrm{O}_{2}, \mathrm{NaOAC} \\
& \mathrm{THF} / \mathrm{H}_{2} \mathrm{O}, 0^{\circ} \mathrm{C} \\
& 89 \% \\
& \text { 1) } T B S C l \text {, imid. } \\
& \text { DMF, it } \\
& \text { 2) DIBAL-H, toluene, } \\
& -78^{\circ} \mathrm{C} \text { to rt } \\
& \text { 3) PPTS, acetone/ } / \mathrm{H}_{2} \mathrm{O} \text {, } \\
& \text { rt, } 1 \mathrm{~h} \\
& 60 \% \text { (3 steps) }
\end{aligned}
$$
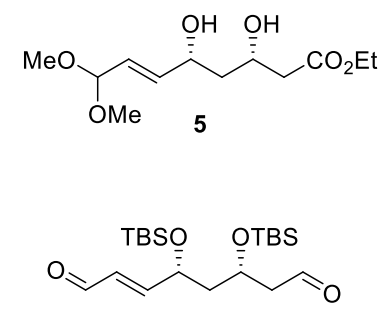

1,3-oxygenation pattern relies on an asymmetric vinyloguous Mukaiyama reaction. ${ }^{21}$ We previously observed that the use of another dienolate partner than Chan's diene 3 proved to be problematic at the cleavage of the 1,3-dioxin-4-one-derivative; therefore, we turned to the Ramesh protocol ${ }^{24}$ using the chiral titanium(IV)-1,1'-binaphtho complex (20\% loading) followed by TBAF deprotection of the trimethylsilyl ether to give the requisite $\delta$-hydroxy- $\beta$-ketoester 4 in $58 \%$ yield (over two steps) with $92 \%$ ee. ${ }^{23}$ Diethyl methoxyborane treatment followed by the successive addition of sodium borohydride at $-78{ }^{\circ} \mathrm{C}$ provided the syn-diol 5 in $89 \%$ yield with high selectivity (de = $90 \%) .^{25}$

The protection of the alcohols as their TBS-ethers was followed by the chemoselective DIBAL-H reduction of the carboxylic ester moiety prior to the acetal deprotection, which relieves the formyl-enal Michael substrate $\mathbf{6}$ and permits the chromatographic removal of the undesired anti-isomer in $60 \%$ yield over three steps.

The intramolecular organocatalyzed Michael addition investigations are described in Table 1, and because the resulting bis-aldehyde could be instable, the crude reaction mixture was treated with $\mathrm{NaBH}_{4}$ to isolate the corresponding diol. The intramolecular $\mathrm{C}-\mathrm{C}$ bond formation of formyl-enal derivatives was originally demonstrated with the stoichiometric use of achiral or chiral amines by the Schreiber group in 1986. ${ }^{18}$ Later, List and coworkers described an enantioselective organocatalytic version on a naked substrate. ${ }^{19}$ Finally, the MacMillan group showed diastereoselective modulation depending on the solvent and enantiomer of the organocatalyst used. $^{20}$ 
Table 1. Effect of the Catalyst and the Solvent in the Organocatalyzed Michael Addition<smiles>CC1NC(=O)C(Br)N1Cl</smiles><smiles>O=C(O)C1CCCN1</smiles>

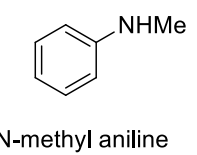

(PhNHMe)

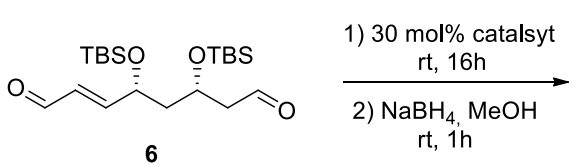

TBSO

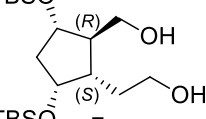

TBSO 7

\begin{tabular}{|c|c|c|c|}
\hline entry & catalyst & solvent & results and isolated yield $(\mathrm{s})$ of $7^{a}$ \\
\hline 1 & 8 or ent -8 & $\mathrm{CHCl}_{3}$ & degradation \\
\hline 2 & L-proline & $\mathrm{CHCl}_{3}$ & $\left(34,34^{b}\right)$ \\
\hline 3 & D-proline & $\mathrm{CHCl}_{3}$ & $\left(36,34^{b}\right)$ \\
\hline 4 & L-proline & DMSO & $\left(27,28^{b}\right)$ \\
\hline 5 & L-proline & $\mathrm{CH}_{3} \mathrm{CN}$ & $\left(32,30^{b}\right)$ \\
\hline 6 & L-proline & $\mathrm{MeOH}$ & $\left(16,18^{b}\right)$ \\
\hline 7 & L-proline & $i-\mathrm{Pr}_{2} \mathrm{O}$ & (38) \\
\hline 8 & L-proline & MTBE & (42) \\
\hline 9 & L-proline & $\mathrm{Et}_{2} \mathrm{O}$ & (51) \\
\hline 10 & L-proline & THF & $\left(55^{c}, 42^{b}\right)$ \\
\hline 11 & L-proline & THF & $\left(56^{c, d}\right)$ \\
\hline 12 & 9 or ent- 9 & THF & reduced SM \\
\hline 13 & 10 or ent -10 & THF & reduced SM \\
\hline 14 & PhNHMe & $\mathrm{CHCl}_{3}$ & reduced SM \\
\hline 15 & trifluoroacetic acid & THF & reduced SM \\
\hline
\end{tabular}

${ }^{a}$ Unless otherwise noted, the reaction was performed by employing 6 $(0.13 \mathrm{mmol})$ and the organocatalyst $(0.04 \mathrm{mmol}, 30 \mathrm{~mol} \%)$ in solvent $(3 \mathrm{~mL})$ at room temperature for $16 \mathrm{~h}$. No full conversion was observed. The aldol product mixture was treated with $\mathrm{NaBH}_{4}(0.39$ $\mathrm{mmol}$ ), and the diol was characterized. See the Supporting Information for details. ${ }^{b} 4 \mathrm{~h}$ reaction time, no full conversion, ${ }^{c}$ Full conversion after $16 \mathrm{~h} .{ }^{d} \mathrm{On}$ a $1 \mathrm{~g}(2.5 \mathrm{mmol})$ scale at room temperature for $16 \mathrm{~h}$.

List's protocol that described the almost exclusive 1,2-trans configuration of the corresponding Michael reaction adduct ${ }^{19}$ gave a complete degradation of the starting material 6 with imidazolidinone catalyst 8 or its enantiomer after $4 \mathrm{~h}$ (Table 1 , entry 1). MacMillan's L-proline thermodynamic control protocol in $\mathrm{CHCl}_{3}{ }^{20}$ exclusively provided the requisite trans isomer 7 as the sole observable isomer (out of the four possible ones) in $34 \%$ yield (no full conversion after 4 or $16 \mathrm{~h}$, Table 1 , entry 2). Interestingly, D-proline as a catalyst afforded the same stereoisomer in a similar yield (Table 1, entry 3). Solvent screening with L-proline as the catalyst showed that highly polar solvents used by MacMillan for kinetic control $(\mathrm{MeOH}$, $\mathrm{CH}_{3} \mathrm{CN}$, and DMSO; Table 1, entries 4-6) resulted in lower yields still with total 1,2-trans selectivity. Ether solvents proved to be more satisfactory (Table 1, entries 7-10), as the best result was observed with $\mathrm{Et}_{2} \mathrm{O}$ and THF (Table 1, entries 9 and 10), and only THF afforded full conversion. The gramscale investigation afforded 7 with the same yield and reaction time $(56 \%, 16 \mathrm{~h})$ (Table 1, entry 11). Possible enantiomeric enrichment during the L-proline-catalyzed Michael addition was checked by performing the reaction starting from ent-6 with both L- and D-proline. ent-7 was obtained with the same isolated yields (after $16 \mathrm{~h}$ ), suggesting that no ee enrichment occurred. (This strategy was used because the ee values of 7 or other derivatives could not be obtained.) Other screened

catalysts, such as trifluoromethyl-substituted diarylprolinol 9 or TMS-derived 10 (both enantiomers) in THF, gave only the recovered starting material (Table 1 , entries 12 and 13 ).

Similarly, the achiral $\mathrm{N}$-methyl aniline (PhNHMe) reagent used in Schreiber's protocol ${ }^{18}$ gave no conversion (Table 1, entry 14). The efficiency of both enantiomers of proline and the poor results of other catalysts led us to consider the possibility of an acid-catalyzed mechanism, but the use of trifluoroacetic acid resulted in no conversion (Table 1, entry 15).

The configuration of compound 7 was assigned as a (1S,2R)-trans isomer thanks to NOESY experiments on its corresponding lactone and comparisons with two other known diastereoisomers of $7 .^{23}$ The above results showed the difficulty in predicting the diastereomeric outcome of this intramolecular reaction, as we observed that compound 6 overcomes the possible chiral catalyst influence, leading to the thermodynamic stable 1,2-trans adduct encountered in the PG skeleton when MacMillan and Mangion substrate showed Land D-proline reversed stereoinductive effects. ${ }^{20}$ Moreover, the reaction may proceed through an iminium-enol, enamine-enal, or even a dual mechanism via open- or close-state transition states, and further investigations (experimental reactions and computational molecular modeling) are ongoing.

Quite surprisingly, and to the best of our knowledge, diol 7 was never considered for PG synthesis, but with this useful skeleton in hand, the first synthesis of 4,11-diepi-4- $\mathrm{F}_{4 \mathrm{t}}-\mathrm{NeuroP}$ 1 continued.

First, the selective enzymatic acetylation of 1,5-nonsymetrical diols developed by our group proved once again to be effective, and diol 7 was regioselectively acetylated at the less hindered alcohol (Scheme 3) with complete selectivity. ${ }^{17 \mathrm{~b}}$ Dess-Martin oxidation of the remaining alcohol afforded the aldehyde substrate, which was directly coupled to the anion of phosphonate $11^{17 \mathrm{a}}$ introducing the backbone of the $\alpha$-chain of 12 in $52 \%$ yield over three steps. The remaining functionaliza-

Scheme 3. Synthesis of 4,11-diepi-4-F tt - NeuroP 1
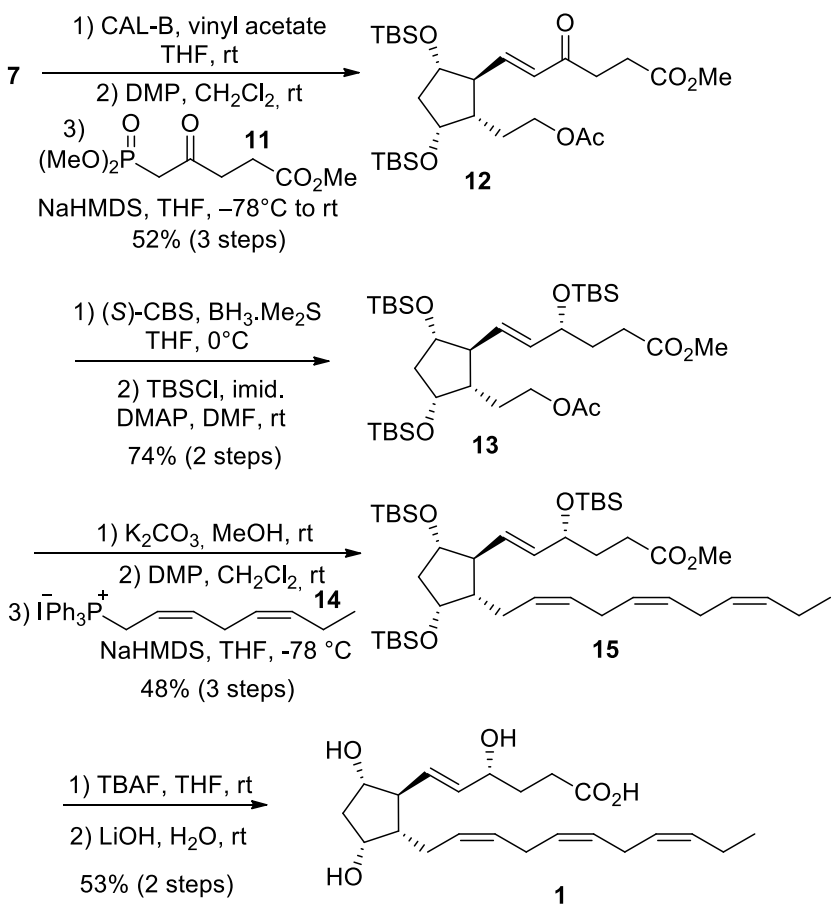
tion to access intermediate 13 required the diastereomeric reduction of the enone 12. Thus the $(S)$-CBS-2-methyloxazaborolidine strategy provided the $(\mathrm{R})$-alcohol product with good selectivity $\left(\mathrm{dr}=88: 12\right.$ by ${ }^{1} \mathrm{H}$ NMR) and was followed by TBS-ether protection in good yield (74\% over two steps). The acetate cleavage of 13 under basic conditions $\left(\mathrm{K}_{2} \mathrm{CO}_{3}\right.$ in $\mathrm{MeOH}$ ) allowed the chromatographic removal of the undesired C4-(S)-epimer. Dess-Martin oxidation and the subsequent $\omega$-chain introduction by a Wittig procedure with the previously described complex ylide of phosphonium salt $14^{26}$ provide 15 in $48 \%$ yield over three steps. Finally, tetra- $n$ butylammonium fluoride (TBAF)-mediated cleavage of the TBS groups led to the corresponding five-membered lactone, which was ring-opened with $\mathrm{LiOH}$ to provide 4,11-diepi-4- $\mathrm{F}_{4 \mathrm{t}^{-}}$ NeuroP 1 in 53\% over two steps.

Our results demonstrated the pertinence of the described organocatalytic disconnection to provide an ideally adapted Corey lactone surrogate for complex PGs in seven steps. Our approach was validated by the first total synthesis of a PG DHA-derived isomer 1, named 4,11-diepi-4- $\mathrm{F}_{4 \mathrm{t}}-\mathrm{NeuroP}$, according to the isoprostane nomenclature in 17 steps from 2 and 3 in $1.6 \%$ overall yield.

Further perspectives include the development of a cascade process, as one could envisage that the known 4-hydroxy-2,6octadienedial $^{27}$ would accommodate a regioselective organocatalytic oxa-Michael addition ${ }^{28}$ (Jørgensen catalyst) to introduce the 1,3-syn diol unit followed by subsequent intramolecular cyclization (this work) to furnish a similar PG skeleton (and orthogonal protection of the 1,3-diol). Recent investigations on catalytic intramolecular conjugate additions of aldehyde-derived enamines to $\alpha, \beta$-unsaturated esters could also promise an alternative approach to the above one-pot process where no regioselective oxa-Michael reaction would be required. $^{29}$

Finally, the analytical relevance of 4,11-diepi-4- $\mathrm{F}_{4 \mathrm{t}}-\mathrm{NeuroP} \mathbf{1}$ is currently being studied in our lipidomics laboratory, and its biologically potential is also under scrutiny.

\section{ASSOCIATED CONTENT}

\section{SI Supporting Information}

The Supporting Information is available free of charge at https://pubs.acs.org/doi/10.1021/acs.orglett.0c02553.

\section{AUTHOR INFORMATION}

\section{Corresponding Authors}

Camille Oger - Institut des Biomolecules Max Mousseron UMR 5247, CNRS, ENSCM, Universite de Montpellier, Montpellier 34093 Cedex 05, France; 이이. ord.org/000-0002-51775792; Email: camille.oger@umontpellier.fr

Jean-Marie Galano - Institut des Biomolecules Max Mousseron UMR 5247, CNRS, ENSCM, Universite de Montpellier, Montpellier 34093 Cedex 05, France; O orcid.org/00000001-6412-4967; Email: jean-marie.galano@umontpellier.fr

\section{Authors}

Johanna Revol-Cavalier - Institut des Biomolecules Max Mousseron UMR 5247, CNRS, ENSCM, Université de Montpellier, Montpellier 34093 Cedex 05, France
Valérie Bultel-Poncé - Institut des Biomolecules Max Mousseron UMR 5247, CNRS, ENSCM, Universite de Montpellier, Montpellier 34093 Cedex 05, France

Alexandre Guy - Institut des Biomolecules Max Mousseron UMR 5247, CNRS, ENSCM, Université de Montpellier, Montpellier 34093 Cedex 05, France

Thierry Durand - Institut des Biomolecules Max Mousseron UMR 5247, CNRS, ENSCM, Université de Montpellier, Montpellier 34093 Cedex 05, France

Complete contact information is available at:

https://pubs.acs.org/10.1021/acs.orglett.0c02553

\section{Notes}

The authors declare no competing financial interest.

\section{ACKNOWLEDGMENTS}

We acknowledge the University of Montpellier (doctoral fellowship of J. R.-C.) and the CNRS. We thank Aurélien Lebrun from the Laboratoire de Mesure Physique for the NOESY experiments.

\section{REFERENCES}

(1) (a) Corey, E. J.; Weinshenker, N. M.; Schaaf, T. K.; Huber, W. J. Am. Chem. Soc. 1969, 91, 5675-5677. (b) Corey, E. J.; Ensley, H. E. J. Am. Chem. Soc. 1975, 97, 6908-6909. (c) Corey, E. J.; Loh, T. P. J. Am. Chem. Soc. 1991, 113, 8966-8967.

(2) (a) Stork, G.; Isobe, M. J. Am. Chem. Soc. 1975, 97, 6260-6261. (b) Suzuki, M.; Yanagisawa, A.; Noyori, R. J. Am. Chem. Soc. 1985, 107, 3348-334. (c) Arnold, L. A.; Naasz, R.; Minnaard, A. J.; Feringa, B. L. J. Am. Chem. Soc. 2001, 123, 5841-5842.

(3) (a) Nugteren, D. H.; Van Dorp, D. A.; Bergström, S.; Hamberg, M.; Samuelsson, B. Nature 1966, 212, 38-39. (b) Bergstrom, S.; Sjovall, J.; Pihl, A.; Almin, K. E.; Magneli, A.; Pestmalis, H.; Asbrink, S. Acta Chem. Scand. 1957, 11, 1086-1086. (c) Bergström, S.; Sjövall, J.; Heath, R. G.; Varde, E.; Westin, G. Acta Chem. Scand. 1960, 14, $1693-1700$.

(4) Smith, W. L.; Urade, Y.; Jakobsson, P.-J. Chem. Rev. 2011, 111, $5821-5865$.

(5) Funk, C. D. Science 2001, 294, 1871-1875.

(6) Das, S.; Chandrasekhar, S.; Yadav, J. S.; Grée, R. Chem. Rev. 2007, 107, 3286-3337.

(7) Morrow, J. D.; Hill, K. E.; Burk, R. F.; Nammour, T. M.; Badr, K. F.; Roberts, L. J. Proc. Natl. Acad. Sci. U. S. A. 1990, 87, 9383-9387.

(8) Jahn, U.; Galano, J. M.; Durand, T. Angew. Chem., Int. Ed. 2008, 47, 5894-5955.

(9) (a) Roberts, L. J.; Montine, T. J.; Markesbery, W. R.; Tapper, A. R.; Hardy, P.; Chemtob, S.; Dettbarn, W. D.; Morrow, J. D. J. Biol. Chem. 1998, 273, 13605-13612. (b) Yin, H.; Musiek, E. S.; Gao, L.; Porter, N. A.; Morrow, J. D. J. Biol. Chem. 2005, 280, 26600-26611.

(10) Roy, J.; Oger, C.; Thireau, J.; Roussel, J.; Mercier-Touzet, O.; Faure, D.; Pinot, E.; Farah, C.; Taber, D. F.; Cristol, J.-P.; Lee, J. C. Y.; Lacampagne, A.; Galano, J.-M.; Durand, T.; Le Guennec, J.-Y. Free Radical Biol. Med. 2015, 86, 269-278.

(11) Lacampagne, A.; Jean-Yves, L. G.; Bultel-Poncé, V.; Galano, J.M.; Guy, A.; Durand, T.; Oger, C.; Matecki, S.; Dridi, H.; Thireau, J.; Roy, J. WO2015197562 (A1), 2015.

(12) (a) Coulthard, G.; Erb, W.; Aggarwal, V. K. Nature 2012, 489, 278-281. (b) Prévost, S.; Thai, K.; Schützenmeister, N.; Coulthard, G.; Erb, W.; Aggarwal, V. K. Org. Lett. 2015, 17, 504-507. (c) Pelšs, A.; Gandhamsetty, N.; Smith, J. R.; Mailhol, D.; Silvi, M.; Watson, A. J. A.; Perez-Powell, I.; Prévost, S.; Schützenmeister, N.; Moore, P. R.; Aggarwal, V. K. Chem. - Eur. J. 2018, 24, 9542-9545.

(13) Umekubo, N.; Suga, Y.; Hayashi, Y. Chem. Sci. 2020, 11, 12051209. 
(14) (a) Hayashi, Y.; Umemiya, S. Angew. Chem., Int. Ed. 2013, 52, 3450-3452. (b) Kawauchi, G.; Umemiya, S.; Taniguchi, T.; Monde, K.; Hayashi, Y. Chem. - Eur. J. 2018, 24, 8409-8414.

(15) Edwards, J. T.; Merchant, R. R.; McClymont, K. S.; Knouse, K. W.; Qin, T.; Malins, L. R.; Vokits, B.; Shaw, S. A.; Bao, D.-H.; Wei, F.L.; Zhou, T.; Eastgate, M. D.; Baran, P. S. Nature 2017, 545, 213218.

(16) (a) Xu, C.; Shen, X.; Hoveyda, A. H. J. Am. Chem. Soc. 2017, 139, 10919-10928. (b) Li, J.; Ahmed, T. S.; Xu, C.; Stoltz, B. M.; Grubbs, R. H. J. Am. Chem. Soc. 2019, 141, 154-158. (c) Nicolaou, K. C.; Pulukuri, K. K.; Rigol, S.; Peitsinis, Z.; Yu, R.; Kishigami, S.; Cen, N.; Aujay, M.; Sandoval, J.; Zepeda, N.; Gavrilyuk, J. J. Org. Chem. 2019, 84, 365-378.

(17) (a) Oger, C.; Bultel-Poncé, V.; Guy, A.; Balas, L.; Rossi, J.-C.; Durand, T.; Galano, J.-M. Chem. - Eur. J. 2010, 16, 13976-13980.

(b) Oger, C.; Marton, Z.; Brinkmann, Y.; Bultel-Poncé, V.; Durand, T.; Graber, M.; Galano, J.-M. J. Org. Chem. 2010, 75 (6), 1892-1897.

(18) Schreiber, S. L.; Meyers, H. V.; Wiberg, K. B. J. Am. Chem. Soc. 1986, 108, 8274-8277.

(19) (a) Hechavarria Fonseca, M. T.; List, B. Angew. Chem., Int. Ed. 2004, 43, 3958-3960.

(20) Mangion, I. K.; MacMillan, D. W. C. J. Am. Chem. Soc. 2005, 127, 3696-3697.

(21) Denmark, S. E.; Heemstra, J. R.; Beutner, G. L. Angew. Chem., Int. Ed. 2005, 44, 4682-4698.

(22) Rees, M. S.; van Kuijk, F. J. G. M.; Siakotos, A. N.; Mundy, B. P. Synth. Commun. 1995, 25, 3225-3236.

(23) See the Supporting Information.

(24) (a) Ramesh, P.; Raju, A.; Fadnavis, N. W. Helv. Chim. Acta 2016, 99, 70-72. (b) Soriente, A.; De Rosa, M.; Stanzione, M.; Villano, R.; Scettri, A. Tetrahedron: Asymmetry 2001, 12, 959-963.

(25) Chen, K.-M.; Hardtmann, G. E.; Prasad, K.; Repič, O.; Shapiro, M. J. Tetrahedron Lett. 1987, 28, 155-158.

(26) (a) Michaud, S.; Viala, J. Tetrahedron 1999, 55, 3019-3024. (b) Durand, T.; Guy, A.; Vidal, J.-P.; Viala, J.; Rossi, J.-C. Tetrahedron Lett. 2000, 41, 3859-3862.

(27) BouzBouz, S.; Cossy, J. Org. Lett. 2001, 3, 1451-1454.

(28) Bertelsen, S.; Dinér, P.; Johansen, R. L.; Jørgensen, K. A. J. Am. Chem. Soc. 2007, 129, 1536-1537.

(29) Girvin, Z. C.; Lampkin, P. P.; Liu, X.; Gellman, S. H. Org. Lett. 2020, 22, 4568-4573. 